\title{
El sugerente e ignoto itinerario del patrimonio arquitectónico en el valle bajo de Cañete
}
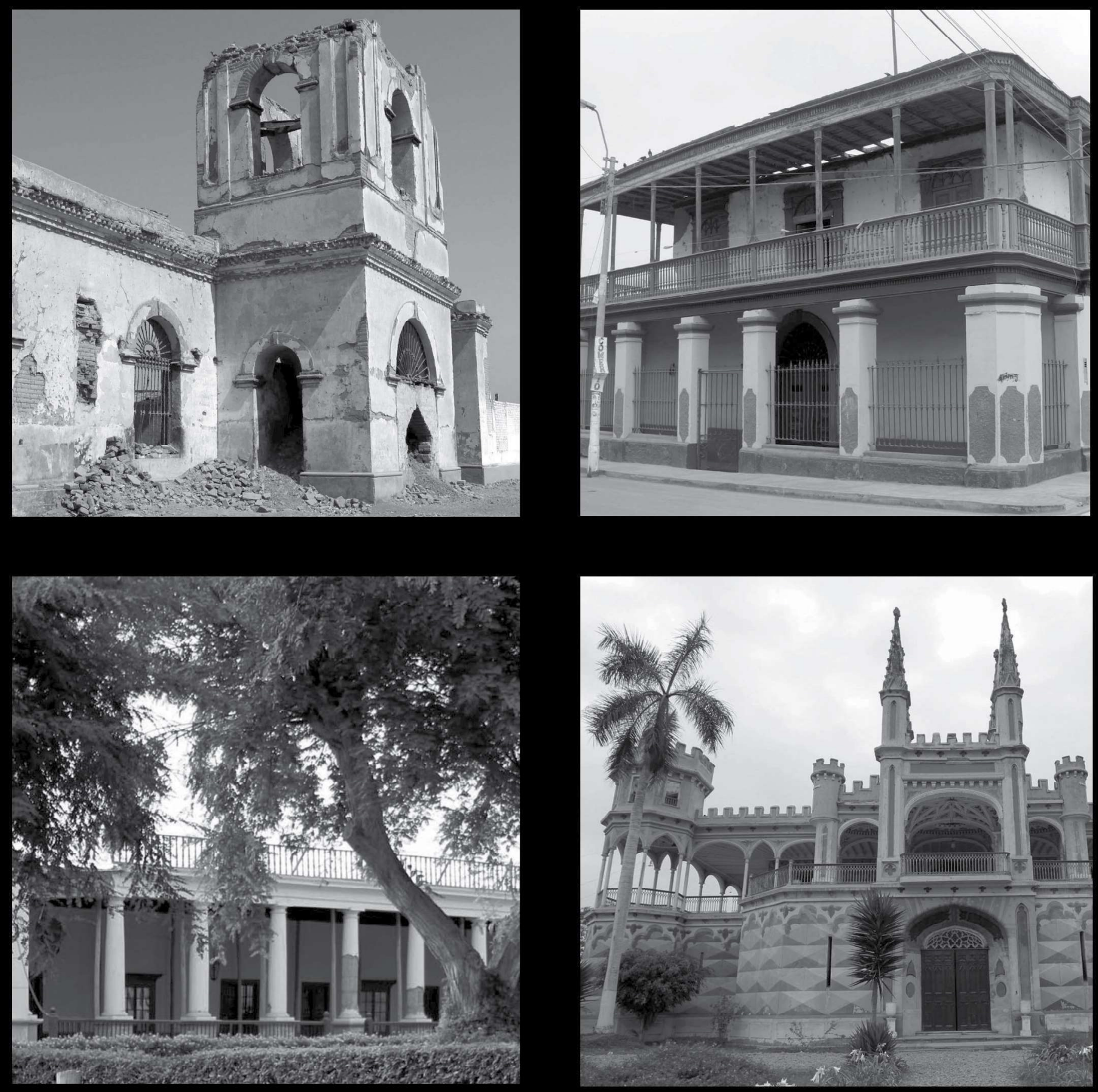

Sandra Negro 
Afirmar que el Perú tiene un inmenso patrimonio cultural, generado a través de su historia, es una suerte de lugar común. Si a esto añadimos sus pisos y nichos ecológicos, entre los más numerosos y variados del planeta, tendremos en nuestras manos una riqueza natural y cultural extraordinaria, que es necesario conocer, para subsecuentemente conservar, tutelar y en especial gestionar.

El valle de Cañete, situado a $143 \mathrm{~km}$. al sur de la ciudad de Lima, no es la excepción. De fácil acceso a través de la autopista Panamericana sur, toma unas 2 horas en automóvil llegar hasta el límite norte del valle (km. 132), formado por el centro poblado y balneario de Cerro Azul, que es la desembocadura hacia el oeste de la quebrada de Ihuanco. El área de cultivo hacia el sur es extensa, generando una ancha franja de tierras agrícolas que corre paralela al borde costero a lo largo de $18 \mathrm{~km}$. Finaliza en las inmediaciones de la desembocadura del río Cañete, en las localidades de Herbay Bajo y Las Arenas, límite final con Pampa Clarita y sus tierras desérticas.

El patrimonio arquitectónico existente en el valle bajo es significativo, si bien para el común de las personas resulta poco conocido. Cuenta con un nutrido conjunto de sitios arqueológicos, que corroboran una consistente ocupación cultural por lo menos desde el año o hasta la llegada de los europeos a la región en 1534 . Entre éstos podemos mencionar como los de mayor significación los siguientes:

1. Los Huacones o Vilcahuasi: conjunto monumental de unas 80 hectáreas de extensión, situado a la altura del km. 138 de la autopista Panamaricana sur. Hacia el este y justamente a través del centro poblado Santa Cruz, se ingresa a una senda no pavimentada a lo largo de poco menos de un kilómetro. Los investigadores Carlos Williams y Manuel Merino, en su Inventario, catastro y delimitación del patrimonio arqueológico del valle de Cañete (1974), lo consideraron arquitectónicamente como el más importante de todo el valle bajo. En el conjunto han sido identificados 11 sectores con un total de 25 pirámides truncas, separadas por espacios abiertos, tales como plazas y patios. Hasta el presente no cuenta con excavaciones arqueológicas, a pesar de su importancia y complejidad formal. Williams y Merino reseñaron haber recogido fragmentos de cerámica de superficie pertenecientes a los periodos Intermedio Temprano (o-60o d.C.), Intermedio Tardío (1000-1460 d.C.) e Inka (1460-1532 d.C.).

2. Cerro del Oro: gigantesco conjunto monumental de unas 120 hectáreas, ubicado a la altura del km. 135 de la antigua carretera Panamericana. Hacia el este hay una vía sin pavimentar, que se dirige hacia el centro poblado Laura Caller. Después de unos $500 \mathrm{~m}$. de recorrido, podemos percibir en la colina que se encuentra hacia el norte, un conjunto de muros arqueológicos delimitados por una muralla perimetral. Su desarroIlo es complejo y extenso, con estructuras piramidales, plazas, recintos cuadrangulares y plataformas elevadas. En agosto de 2013, un equipo de investigación identificó y excavó el mausoleo de un personaje de élite de género masculino, que se hallaba dentro de una cámara funeraria rectangular, con una cubierta de lajas dispuestas de manera inclinada a doble vertiente. El rico ajuar estaba formado por más de 100 piezas. La cerámica que acompañaba al personaje es de filiación Wari (Horizonte Medio 600-1000 d.C.) con influencia Nasca (Intermedio Temprano 0-600 d.C).

3. El centro habitacional y ceremonial de Guarco: emplazado en la planicie ubicada entre los cerros Camacho y Centinela, a espaldas de la actual caleta de Puerto Viejo en el centro poblado de Cerro Azul. Se trata de diez conjuntos arquitectónicos asentados sobre la falda baja y media del cerro Camacho hacia la playa sur, así como un conjunto de terrazas edificadas sobre la falda orientada hacia el oeste, que contienen estructuras 
funerarias y otras edificaciones menores. Las excavaciones de la arqueóloga Joyce Marcus (1984) ubican al sitio dentro del Periodo Intermedio Tardío en la región (1000-1460 d.C.), con una ocupación final del Horizonte Tardío o Tawantinsuyu (1460-1532 d.C.). Los diez conjuntos fueron residencias de élite con múltiples habitaciones y patios para labores, tales como la conservación por medio del secado al aire libre de anchovetas y sardinas, así como una chichería para la preparación de azua o chicha de jora, con un área de $110 \mathrm{~m}^{2}$ y que fue excavada en el "conjunto arquitectónico D”. También se halló un extenso número de vasijas de gran tamaño, que estaban semienterradas en el suelo. Las más pequeñas tenían una capacidad de unos 125 litros, mientras que la más grande de todas alcanzaba un volumen almacenable de 2,000 litros. Entre dichas estructuras se encuentran diseminados pequeños edificios con 1 o 2 habitaciones, que en algunos casos pueden llegar hasta 12, a los cuales al presente resulta imposible asignar una única función para todos. En éstos se han hallado bloques de arcilla con improntas de cañas, lo que hace suponer que tales construcciones fueron más precarias -ya que se solucionaron con bajareque- y que probablemente en ellas moraban los pescadores.

4. El "palacio" de Cancharí: ubicado en la parte baja de las ramificaciones de los cerros Tembladera y Candela, hacia el noreste del santuario de Nuestra Señora Madre del Amor Hermoso, edificado al pie de la antigua carretera Panamericana, poco antes de llegar a la ciudad de San Vicente de Cañete. Hasta el presente no ha sido excavado, de modo que su filiación cultural es incierta. Sobre el promontorio rocoso fueron construidas un conjunto de terrazas, que ascienden escalonadamente hasta la cumbre donde se erige la edificación principal. Esta cuenta con dos amplios patios rodeados de cuartos y recintos, resueltos con gruesos muros de adobones. Larrabure y Unanue, así como Middendorf lo describieron como un sitio compuesto por una edificación señorial ("palacio") con un cementerio a corta distancia.

5. La "fortaleza" de Ungará: situada en uno de los promontorios rocosos del ce- rro Pinta, sobre la margen derecha del río Cañete, carece hasta el presente de excavaciones arqueológicas. Por esta razón, su filiación cultural no ha sido determinada y tampoco se trata de una fortaleza en el estricto sentido del término. El sitio ocupa unas 80-100 hectáreas, con un extenso número de terrazas que escalonadamente ocupan las faldas del promontorio. Presenta una considerable complejidad arquitectónica, con sectores amurallados, plazas, conjuntos habitacionales con patios y áreas con tumbas. El material constructivo predominante es el adobón.

Los escasos proyectos de excavación arqueológica llevados a cabo en el valle bajo, previenen que se pueda explicar en la actualidad y de manera consistente la ocupación cultural prehispánica en la región. Por esta razón, en el presente texto he optado por presentar la arquitectura de valor histórico y patrimonial de los siglos XVII al XIX $\mathrm{y}$ ofrecer algunas reflexiones en torno a su estado actual y posibilidades de recuperación.

El primer destino significativo está dentro de los límites del centro poblado y balneario de Cerro Azul, situado en el km. 132 de la autopista Panamericana sur. Se trata de la caleta de Puerto Viejo, la cual en 1830 obtuvo la habilitación para el comercio de cabotaje, que posibilitó la salida al mar de los productos provenientes de los extensos cultivos de caña de azúcar en el valle, así como el guano de las islas próximas. En 1870 el hacendado Henry Swayne, invirtió en la construcción de un muelle de madera y una línea férrea, que transportaba hasta el embarcadero -para ser conducido por mar al Callao y desde allí a Europa-el azúcar producido en haciendas como Santa Bárbara, La Quebrada y Casablanca. El muelle original se hallaba situado en el puerto de La Fortaleza, conocido décadas más tarde con el nombre actual de Puerto Viejo. Allí se erigían las antiguas oficinas de desembarque, las que fueron reconstruidas y adecuadas como viviendas de veraneo a mediados del siglo pasado.

El 3 de abril de 1899 llegó al puerto del Callao el barco Sakura Maru, transportando un contingente de 790 inmigrantes japoneses, contratados para trabajar como braceros en las haciendas costeras. Unos días después, la embarcación acoderó en el 
muelle de La Fortaleza, asignándose 50 individuos a la hacienda Casablanca, mientras que otros 176 se incorporaron a la hacienda Santa Bárbara, ambas a cargo por entonces de la British Sugar company. Actualmente en el malecón frente a la playa, se yergue un monumento conmemorativo con doce pilares, que simbolizan los pioneros japoneses en su desembarco, marcando además el sitio del emplazamiento original del muelle.

Hacia 1917 la caña de azúcar fue desplazada por el cultivo del algodón, lo que impulsó el desarrollo del puerto y consecuentemente el aumento de su población. En 1921 Cerro Azul fue elevado a la categoría de distrito, construyéndose cuatro años más tarde, el actual muelle de madera, más amplio y en un emplazamiento periférico a la caleta de pescadores. Los pobladores comenzaron a prosperar económicamente con las labores vinculadas al puerto.

La aplicación del proceso de la Reforma Agraria a partir de 1969 y la mejora en el trazado de la carretera Panamericana sur -que facilitó la salida por vía terrestre de los productos hacia Lima- generó que el muelle fuera clausurado en 1972, debido al escaso movimiento comercial. Actualmente solo es utilizado por los pescadores artesanales.

En 1974 fue colocado un faro sobre la cúspide del cerro Centinela, que se halla a espaldas de las antiguas oficinas de desembarque del puerto y las actuales viviendas y restaurantes. Lo más contradictorio es que comenzó a funcionar cuando Cerro Azul había cesado su actividad portuaria. Sin embargo, fue el primero instalado en América del Sur para funcionar con paneles de energía solar. Por las noches resulta sugestivo a la distancia, ya que aún desde la carretera Panamericana, su brillante haz de luz orienta a los viajeros.

Saliendo del centro poblado Cerro Azul, podemos tomar dos rutas: la primera es proseguir hacia el sur por la autopista $\mathrm{Pa}$ namericana y la otra, continuar siempre al sur por la antigua carretera Panamericana que nos conduce hacia el poblado de San Luis de Cañete. Con la finalidad de conocer la ex-hacienda Santa Bárbara, es necesario desplazarse hasta el km. 135 de la autopista Panamericana, donde a través de un corto desvío hacia el oeste se llega a los restos de la hacienda. Las fuentes documentales en el Archivo General de la Nación, la sitúan a mediados del siglo XVIII como una hacienda azucarera perteneciente a Fernando Carrillo de Córdova y Mudarra, Marqués de Santa María de Pacoyán. Por entonces la propiedad se hallaba registrada con el nombre de hacienda Huaca y Carrillos y contaba con un trapiche, casa de pailas y casa de purga, para la elaboración de panes de azúcar y mieles.

En 1872 fue adquirida por el hombre de negocios de origen escocés, Henry Swayne Wallace y a partir de allí fue nombrada Santa Bárbara. Dos años más tarde, había sido transformada en un importante centro azucarero, alcanzando anualmente la elaboración de mil toneladas métricas de azúcar y cerca de 38,000 litros de aguardiente de caña. La producción azucarera republicana tuvo un significativo impulso con el empleo de la maquinaria a vapor a partir del último tercio del siglo XIX.

La riqueza de Swayne -lograda con la gestión de importantes haciendas azucareras y algodoneras en el Perú- disminuyó marcadamente en los últimos años de su vida debido a la caída en los precios del azúcar de caña, como consecuencia de los importantes progresos en la industria del azúcar de remolacha en Europa desde 1870 en adelante. Contemporáneamente, el final de la Guerra de Secesión en Estados Unidos de América en 1865, afectó los beneficios obtenidos por la venta del algodón.

Después de su muerte, ocurrida en enero de 1877 , la situación económica de sus haciendas empeoró drásticamente. Durante la guerra del Pacífico (1879-1884), la intervención de la Oficina Británica de Asuntos Extranjeros logró salvar sus propiedades del vandalismo del ejército chileno. En 1900 la deuda financiera de las haciendas, por entonces en manos de sus herederos, había crecido exponencialmente. Por esta razón, su familia negoció un trato con los acreedores, en particular con la casa mercantil Lockett de Liverpool, que dio lugar al establecimiento de la British Sugar Company, la cual adquirió importantes propiedades en Cañete a lo largo de la primera década del siglo XX.

La antigua hacienda, si bien maltrecha por el tiempo, los sismos, la incuria de los propietarios y las autoridades locales y nacionales, es un caso de arquitectura rural e industrial que merece ser rescatada y puesta en valor con un nuevo uso. Al presente cuenta con la vivienda principal de factura 


\section{VALLE BAJO DE CAÑETE. LIMA. PERÚ.}

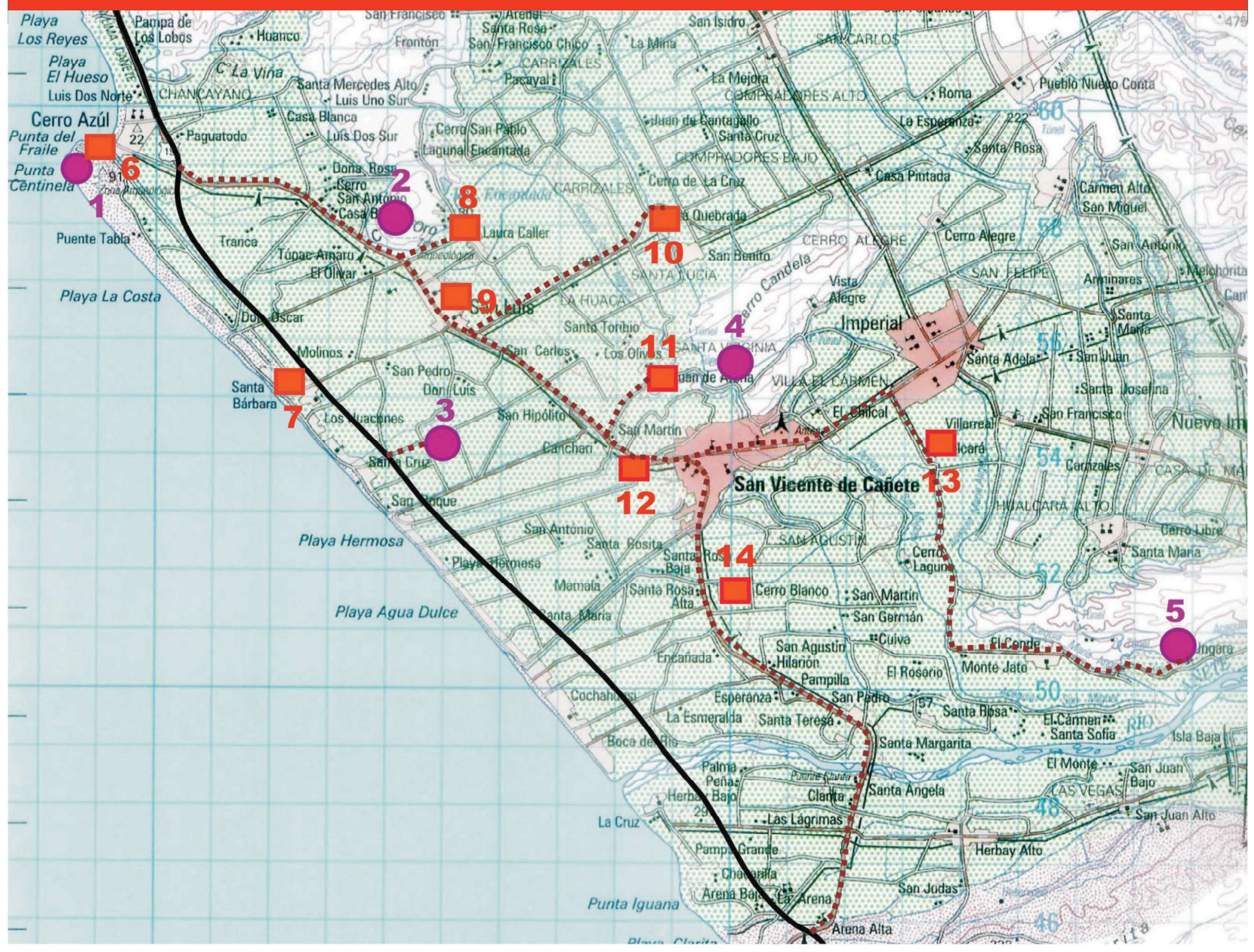

\section{SITIOS ARQUEOLÓGICOS DESTACADOS:}

1. Cerro Azul (señorío Guarco, periodo Intermedio Tardío 1000-1460 d.C.)

2. Cerro del Oro (conjunto con ocupaciones de los periodos Intermedio Temprano y Horizonte Medio, entre los 0 y 1000 años d.C.)

3. Los Huacones o Vilcahuasi (conjunto con ocupaciones de los periodos Intermedio Temprano, Intermedio Tardío e Inka, entre los 0 y los 1532 años d.C.)

4. Cancharí (conjunto del periodo Intermedio Tardío 1000-1460 d.C. ¿?)

5. Ungará (conjunto con ocupaciones del periodo Intermedio Tardío 1000-1460 d.C. y quizás anteriores)

\section{PATRIMONIO ARQUITECTÓNICO:}

6. Puerto Viejo o La Fortaleza en Cerro Azul (puerto y oficinas de desembarque del siglo XIX)

7. Hacienda Santa Bárbara (la casa principal es de mediados del siglo XIX)

8. Hacienda Casablanca (la casa principal es de mediados del siglo XIX)

9. Centro poblado San Luis de Cañete (establecido en 1578, perdura hasta el presente)

10. Hacienda La Quebrada o San Juan Capistrano (la casa principal colapsó en el terremoto de 2007)

11. Hacienda San Juan de Arona (la casa principal es de mediados del siglo XIX)

12. Hacienda Montalbán (la casa principal es probablemente de finales del siglo XVIII, con refacciones en los dos siglos siguientes)

13. Hacienda San Pedro Abad o Hualcará (los restos de la casa principal y capilla son del siglo XIX)

14. Hacienda Unanue (la casa principal es del último tercio del siglo XIX)

Fuente: mapa del Instituto Geográfico Nacional, hoja Cañete, 1:100,000

Localización de sitios patrimoniales arqueológicos y arquitectónicos: S. Negro, 2014 

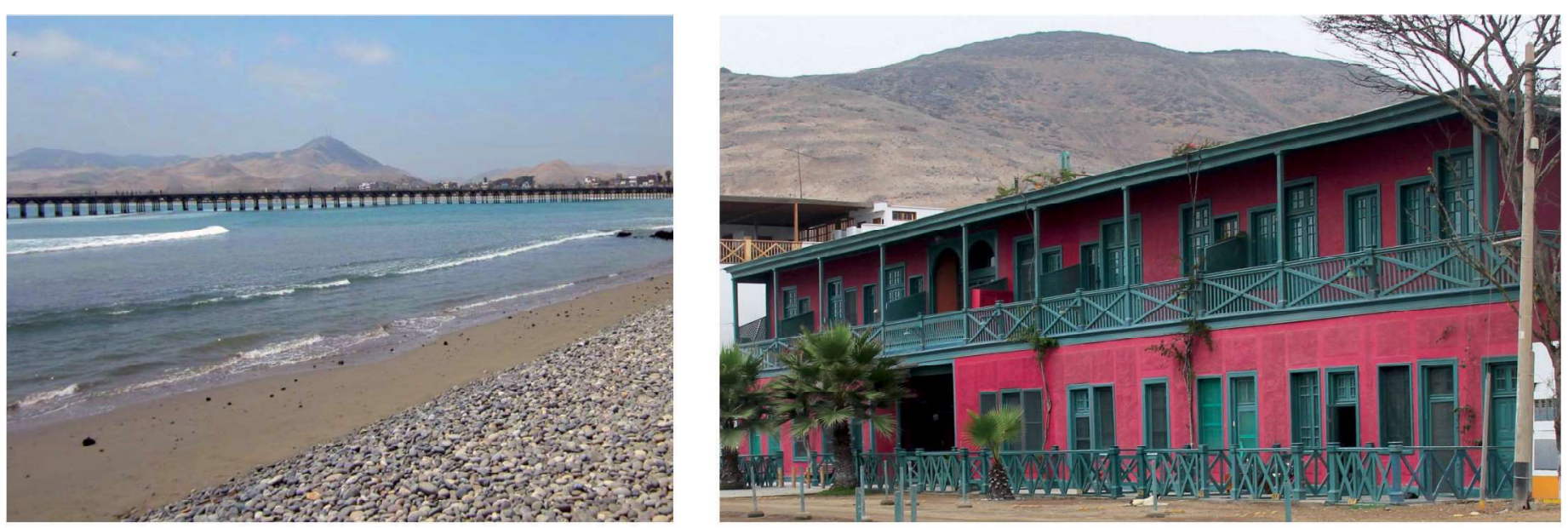

Puerto Viejo en Cerro Azul. Izq: playa con el muelle construido en 1925. Continuó en funciones de manera restringida hasta 1972. Der: Antiguas oficinas de desembarque del puerto, que actualmente funcionan como viviendas de veraneo.

\section{PATRIMONIO \\ ARQUITECTÓNICO EN EL VALLE BAJO DE CAÑETE}

Hacienda Santa Bárbara: sector del antiguo trapiche.

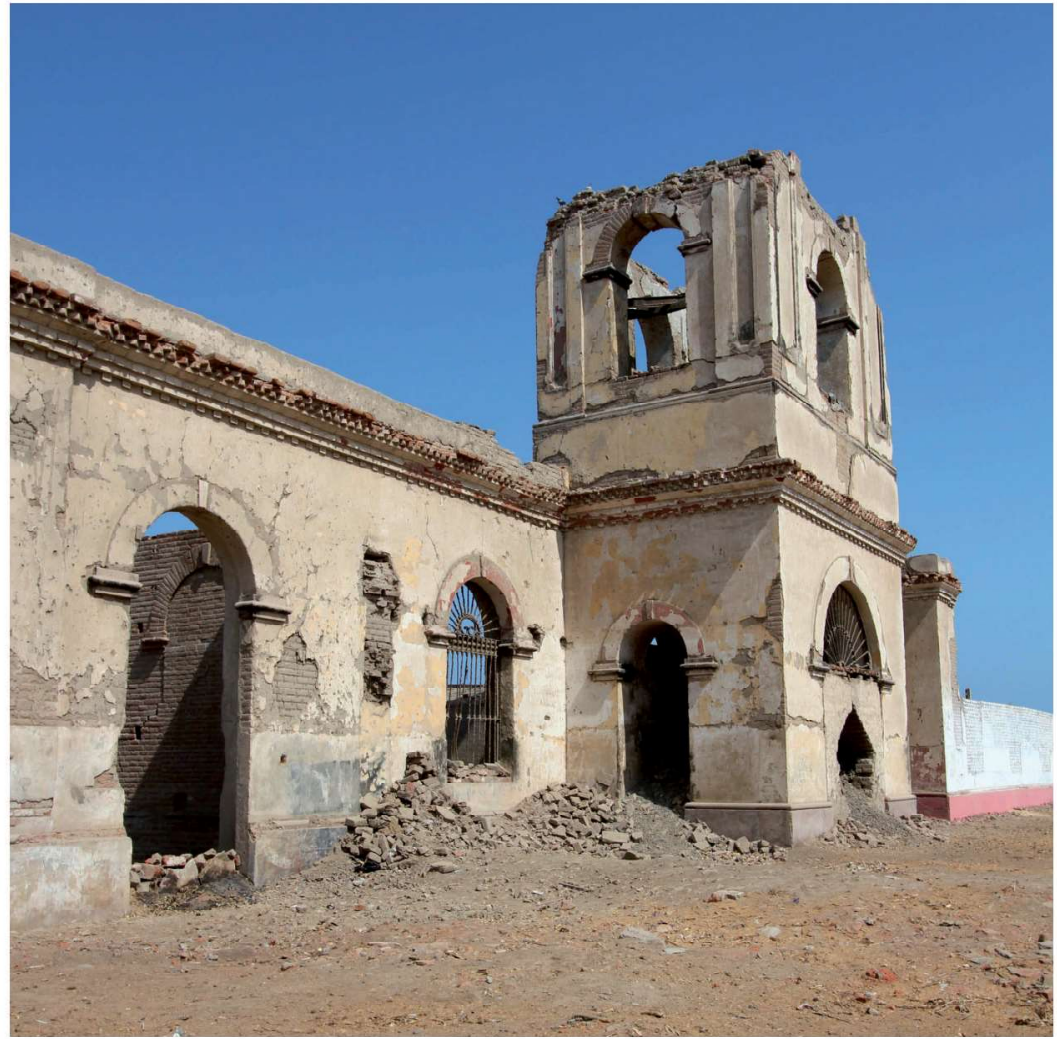

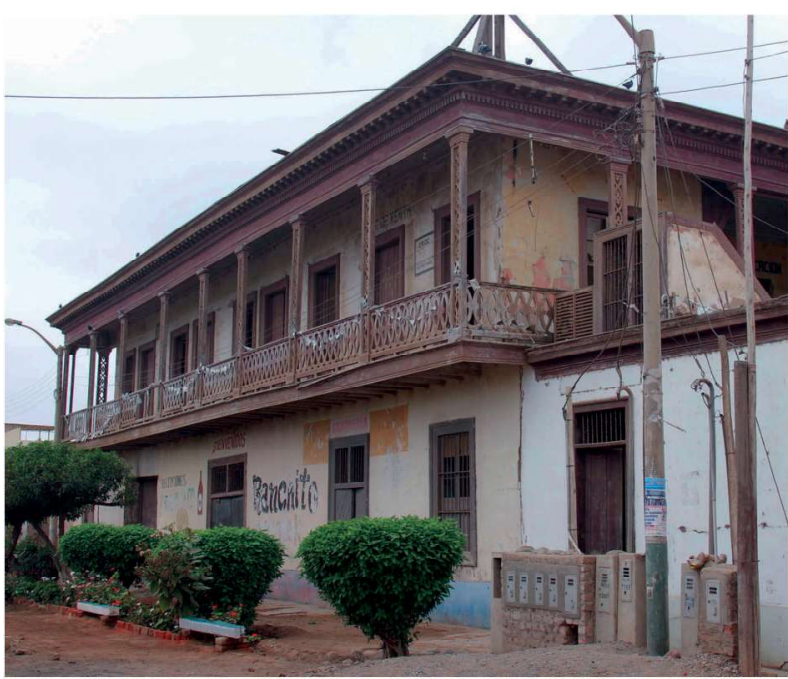

Centro poblado Laura Caller: casa principal de la exhacienda Casablanca, de diseño y ornamentaciones decimonónicas

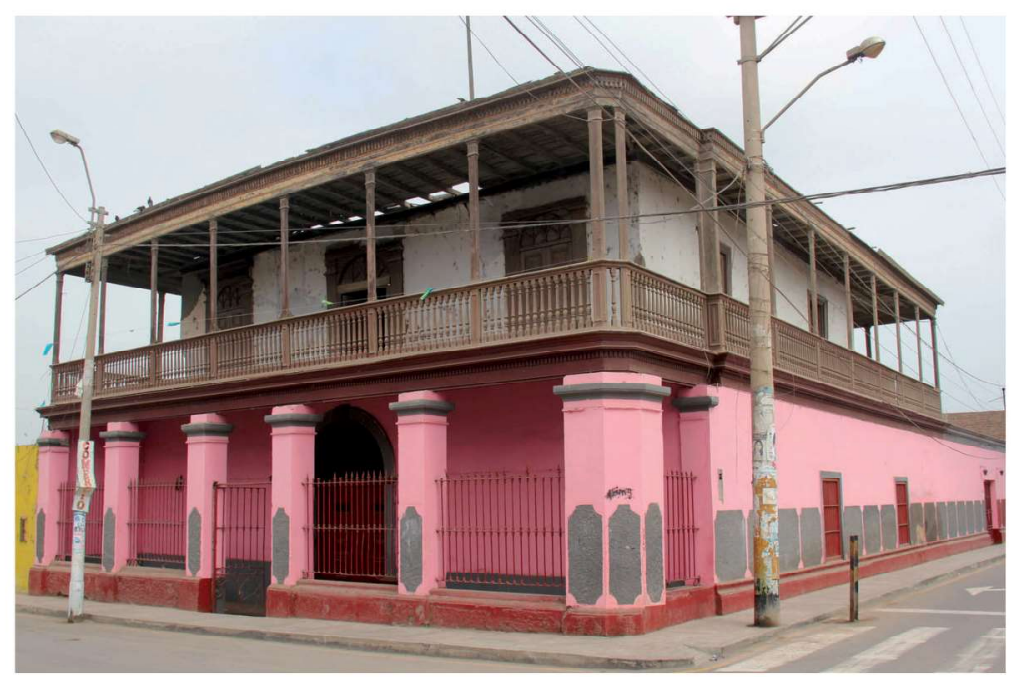

San Luis de Cañete: "Casa de la Colonia China". En el exterior presenta un lenguaje arquitectónico propio del siglo XIX. 
republicana, la misma que si bien ha tenido extensas adiciones, modificaciones y refacciones, conserva formas arquitectónicas, ornamentaciones, carpintería, materiales y técnicas constructivas con valor histórico y patrimonial. El patrimonio industrial está representado por los restos del antiguo trapiche, del cual queda enhiesta la torre principal y la arquería de la fachada. A corta distancia se levanta un inmueble, que por sus características y proximidad al trapiche, hace pensar en un vínculo con la línea férrea que unía esta hacienda con las colindantes. Al presente, exhibe adosado a un muro, el frontón con volutas de un retablo de madera hoy desaparecido. Las decoraciones de rocallas lo sitúan cronológicamente a finales del siglo XVIII y primer tercio del XIX. Hacia el sur y a muy corta distancia de estas edificaciones se halla un montículo arqueológico, el mismo que fue disturbado con la construcción de por lo menos dos hornos para quemar botijas. Los restos de plantas circulares, edificadas con adobes quemados y arcos elaborados con ladrillos recochos, nos señala la existencia de hornos que es necesario datar, pero que su forma, dimensiones y características son similares a aquellos empleados para quemar botijas en Pisco, Ica y Nasca durante los siglos XVIII y XIX.

Para proseguir con nuestro recorrido, debemos regresar por la autopista Panamericana, esta vez hacia el norte hasta llegar nuevamente a la bifurcación de Cerro Azul. Aquí debemos dirigirnos a través de la antigua carretera Panamericana al centro poblado de San Luis de Cañete. Al Ilegar al km. 135, distinguimos a la izquierda un monumento conmemorativo a la música afroperuana que nos da la bienvenida al distrito. Precisamente en la esquina de dicho monumento hay una carretera sin pavimentar, que se dirige con rumbo este hacia el sitio arqueológico de Cerro del Oro y el centro poblado Laura Caller, este último a tan sólo $1.5 \mathrm{~km}$ de distancia.

Aquí se erige la casa principal de la antigua hacienda Casablanca. A finales del siglo XVII pertenecía al presbítero don Pedro Rodríguez Maldonado. Después de varias ventas, en 1727 la propiedad estuvo en manos de don Agustín de Landaburu y Goycochea, corregidor de Cañete. Sus herederos la vendieron en 1762 a la Orden de los Crucíferos de San Camilo. Con los nuevos propietarios, la hacienda inició un periodo de florecimiento, en un momento coyuntural favorable para la economía azucarera. En 1832 estuvo en manos de Henry Swayne, quien también adquirió cuatro décadas más tarde, la hacienda Santa Bárbara.

Con la aplicación de la ley de Reforma Agraria en 1969, las haciendas pasaron a ser Cooperativas Agrarias de Producción (CAP). Frente al poco éxito de su gestión, debido en gran medida a la mala administración de sus dirigentes, tanto por desconocimiento, como por la crisis del agro de 1981, los agricultores optaron por organizar las cooperativas en parcelas individuales. Un buen número de CAPs se transformaron en Cooperativas Agrarias de Trabajadores y luego en Cooperativas Agrarias de Usuarios (CAU), donde cada parcela era manejada individualmente, si bien la cooperativa mantenía el control de algunas actividades difíciles de dividir y realizar individualmente. En la actualidad, casi todas las cooperativas están desmembradas y las tierras parceladas, como es el caso de las antiguas haciendas Casablanca, La Quebrada, Hualcará y San Benito, hoy transformadas en centros poblados.

Sin duda es importante conocer la arquitectura republicana del siglo XIX que ha perdurado. El diseño de la casa principal de la hacienda fue organizado en dos pisos compactos con varias crujías paralelas. El primer piso es macizo, con puertas y ventanas que abren sobre las fachadas. En el segundo nivel se diseñó un balcón que envuelve las crujías de la vivienda por sus cuatro lados. Es de madera y sustentado en la prolongación de los cuartones o vigas del techo del primer piso. La cubierta del balcón no se apoya en pies derechos o pilarotes, como era usual, sino en paneles de madera perforados con diseños de guilloques y cartones. El remate es un entablamento de madera de excelente calidad, con el arquitrabe y friso lisos, mientras que la cornisa tiene un voladizo significativo, apoyado decorativamente en modillones. Los vanos de las puertas y ventanas tienen postigos de madera, enmarcados con polseras de diseño típicamente republicano. La casa presenta una adición de un solo piso hacia el sur, con una cronología actualmente indeterminada. Tiene muros de quincha y ventanas teatinas en el techo. Hacia el sur presenta una fachada con una ventana volada, 
cerrada con una reja de hierro del siglo XIX o principios del XX. La galería delantera está sustentada en columnas de madera con basas y capiteles de molduras simples. En este local funcionan las oficinas de la CAP Túpac Amaru $n^{\circ} 3$.

Frente a la fachada principal de la vivienda, se erige una capilla edificada recientemente. Sin embargo, el cubo bajo de la torre de la epístola, presenta rasgos contemporáneos con la arquitectura republicana de la vivienda, ya que tiene un diseño de pilastras pareadas, ornamentadas con un almohadillado en planchas.

Esta arquitectura, que debe ser rescatada y puesta en valor, no está debidamente tutelada por las instancias estatales pertinentes, ya que no ha sido reconocida como patrimonial. Por esta razón, en tiempos recientes existe la intención de demolerla para utilizar el área del terreno con otros fines. A corta distancia se yerguen dos palmeras reales, mudas testigos de los tiempos del florecimiento de la hacienda. Estas también están bajo la amenaza de ser taladas, a pesar de ser consideradas por muchos pobladores como un símbolo histórico.

Es posible salir de Casablanca por una senda asfaltada que desemboca en la antigua carretera Panamericana en el km. 137. Un kilómetro más adelante se sitúa San Luis de Cañete, que es uno de los dieciséis distritos de la provincia. Durante el gobierno del virrey Andrés Hurtado de Mendoza y Cabrera, II marqués de Cañete (1556-1560), se fundó la villa de españoles Santa María de Cañete, ubicada en el valle del Guarco. Los veinticinco vecinos empadronados por orden de privilegio, recibieron un solar por cada cabeza de familia. El oficio de la mayor parte de los pobladores de la recién fundada villa, estaba vinculado con la agricultura y la ganadería. Por esta razón, en breve tiempo los nuevos habitantes se dispersaron hacia sus huertas, chacras y estancias, abandonando el lugar. A principios de 1558, el virrey autorizó la segunda fundación de la villa a partir de la solicitud de Hernando Alonso, procurador de la abandonada Santa María. Una vez refundada y con una nueva repartición de solares, los pobladores comenzaron a avecindarse y edificar sus viviendas. No obstante, una catástrofe se abatió sobre ella tan solo dos décadas después. El 17 de julio de 1578, la costa central fue sacudida por un fuerte terremoto, que dejó en escombros a la escasamente consolidada villa. A finales de ese mismo año y en pleno proceso de reconstrucción, sufrió el ataque y saqueo del pirata Francis Drake.

Ante los descontrolados sucesos, los moradores huyeron espantados y se establecieron en las inmediaciones del Cerro de las Sepulturas -hoy conocido con el nombre de Cerro del Oro- donde comenzaron a edificar sus viviendas, así como una iglesia bajo la advocación de San Luis, Obispo de Tolosa y la tutela espiritual de los franciscanos. El poblado tuvo un significativo auge económico debido al comercio, ya que se hallaba al pie del camino real y estaba inserto dentro de una región con propiedades agrícolas y ganaderas en expansión.

En febrero de 1687 de manera paulatina, los moradores abandonaron el poblado de San Luis Obispo, optando por avecindarse en la recién creada villa de San Vicente Mártir. La razón principal fue la persistencia de los ataques de piratas y corsarios, que llegaron a apresar al corregidor Martín de la Cueva y al párroco P. Matías Cascante. A partir de entonces, la escasamente habitada villa de San Luis Obispo tomó el nombre de Pueblo Viejo y San Vicente Mártir pasó a ser conocido como Pueblo Nuevo. Esta última es actualmente la ciudad de San Vicente de Cañete, capital de la provincia del mismo nombre.

Medio siglo más tarde, lentamente San Luis de Cañete se fue nuevamente repoblando, principalmente porque funcionaba como núcleo comercial de las haciendas en las inmediaciones, dedicadas principalmente a los cultivos de la caña de azúcar y algodón. La iglesia de San Luis de Tolosa -que fuera edificada por primera vez en 1578- ha llegado hasta el presente, si bien gravemente afectada por el terremoto de 2007. Este inmueble, que debió tener varias reconstrucciones a través del tiempo, presenta una planta en cruz latina con brazos cortos, que cronológicamente corresponde a una refacción del siglo XVIII. Sobre el crucero se levantaba una cúpula de media naranja sobre pechinas, resuelta con cerchas de madera y quincha que colapsó con el último movimiento telúrico. Está declarada como inmueble con valor patrimonial desde el año 1991, lo que ha prevenido su demolición.

En la avenida principal del centro poblado de San Luis de Cañete, se erige una edi- 